\title{
Is the Sulfonamide Group of Tamsulosin the Main Factor in the Pathophysiology of Floppy Iris Syndrome?
}

\author{
๑ Ahmet Ürkmez ${ }^{1}$, ๑ Özgür Haki Yüksel ${ }^{2}$ \\ ${ }^{1}$ Department of Urology, Health Science University, Haydarpasa Numune Training and Research Hospital, Istanbul, Turkey \\ ${ }^{2}$ Department of Urology, Health Science University, Fatih Sultan Mehmet Training and Research Hospital, Istanbul, Turkey
}

\begin{abstract}
Intraoperative floppy iris syndrome (IFIS) was first described by Chang et al. in 2005 in using a-blockers. Tamsulosin a selective $\mathrm{a}$-(a) adrenergic receptor (AR) antagonist is a commonly prescribed drug for benign hyperplasia of the prostate (BPH), and it has been shown to have the strongest association with IFIS. Other drugs that predispose to IFIS include alfuzosin, doxazosin, terazosin, finasteride, labetalol, mianserin, chlorpromazine, donepezil and other antipsychotic agents. In literature reviews, the pathophysiological evaluation of IFIS has not yielded clear results. In the present study, we examined this pathophysiological mechanism from a different perspective and somewhat hypothetically analyzed the chemical composition of these drugs. We analyzed their chemical formulas and pharmacological effects in combination. We compared tamsulosin with other IFIS-inducing a-blockers and propose that its sulfonamide group might be a causative factor.

Keywords: Chemical formulas; floppy iris syndrome; sulfonamide bond; tamsulosin.
\end{abstract}

I

ntraoperative floppy iris syndrome (IFIS) was first described by Chang et al. ${ }^{[1]}$ in 2005 using a-blockers. According to this first description, IFIS has three clinical criteria: (a) floppy iris stromal fluctuating with fluid flow, (b) tendency of iris tissue to prolapse from the wound site, and (c) progressive intraoperative papilla narrowing. IFIS can only be diagnosed intra-operatively, and it is associated with serious complications adversely affecting prognosis ${ }^{[2]}$.

Tamsulosin a selective $a-(a)$ adrenergic receptor (AR) antagonist is a commonly prescribed drug for benign hyperplasia of prostate (BPH), and it has been shown to have the strongest association with IFIS. Patients using alfuzosin another a-blocker showed a lesser risk of IFIS development compared with those using tamsulosin ${ }^{[3]}$. Other drugs that predispose to IFIS include doxazosin, terazosin, finasteride, labetalol, mianserin, chlorpromazine, donepezil, and other antipsychotic agents ${ }^{[4-11]}$. Systemic factors that have been implicated for predisposition to IFIS include diabetes and hypertension ${ }^{[12]}$. Saw palmetto (seronea repens), a widely used alternative therapy for BPH, was also associated with IFIS in a few patients ${ }^{[13]}$. In this article, we compared tamsulosin with other IFIS-inducing a-blockers and propose that its sulfonamide group might be a causative factor.

\section{Material and Methods}

In literature reviews, the pathophysiological evaluation of IFIS has not yielded clear results. Most of the studies performed have been tamsulosin-based comparative studies or case reports. In the present study, we examined this pathophysiological mechanism from a different perspective and

Correspondence (iletişim): Ahmet Ürkmez, M.D. Saglik Bilimleri Universitesi, Haydarpasa Numune Egitim ve Arastirma Hastanesi, Uroloji Anabilim Dali, Istanbul, Turkey

Phone (Telefon): +90 5077668300 E-mail (E-posta): ahmeturkmez@hotmail.com

Submitted Date (Başvuru Tarihi): 21.02.2018 Accepted Date (Kabul Tarihi): 04.05.2018

Copyright 2018 Haydarpaşa Numune Medical Journal

This is an open access article under the CC BY-NC license (http://creativecommons.org/licenses/by-nc/4.0/). 
somewhat hypothetically analyzed the chemical composition of these drugs. We analyzed their chemical formulas (Fig. 1) and pharmacological effects in combination (Table 1).

\section{Results}

Terazosin, doxazosin, and alfuzosin are quinazoline derivatives, while tamsulosin is a derivative of methoxybenzene sulfonamide. This structure of tamsulosin is different from non-selective quinazoline derivative a-blockers. When we examined the pathophysiology of association between IFIS and tamsulosin, despite the lack of sufficient amount of evidence, the following mechanisms can be suggested: (a) prolonged stay of tamsulosin in anterior chamber and its irreversible affinity to iris smooth muscle ARs in experimental animal trials and its induction of muscle atrophy; (b) stronger a-1 receptor affinity of tamsulosin compared with that of other a-blockers and its activities potentially mediated via an $1 \mathrm{~L}$ receptor, and (c) affinity of tamsulosin for non-ARs in iris. The interaction in the binding of tamsulosin to a-1 AR subtypes using molecular modelling was reported by Ishiguro et al., ${ }^{14]}$ 2002; According to this report, the functional groups of tamsulosin, i.e., ethylamine nitrogen, sulphonamide nitrogen and methoxy oxygen of the benzene ring may interact with $a-1 A, a-1 B$, and $a-1 D$ ARs. Sulphonamide nitrogen of tamsulosin interacts with a-1D AR. This is probably due to the more acidic natüre of sulphonamide and the long bond lengths of the $\mathrm{C}-\mathrm{S}$ and $\mathrm{S}-\mathrm{N}$ bonds, which would enable the sulphonamide to bind a-1D AR.

Here, we observed that the chemical formula of tamsulosin was different from that of other a-blockers. When we further extrapolated this observation, we detected a sulfonamide group in acetazolamide, which is used in open-angle glaucoma and demonstrates its effects by decreasing the amount of humor aqueous with resultant vasodilator effects on eyes.

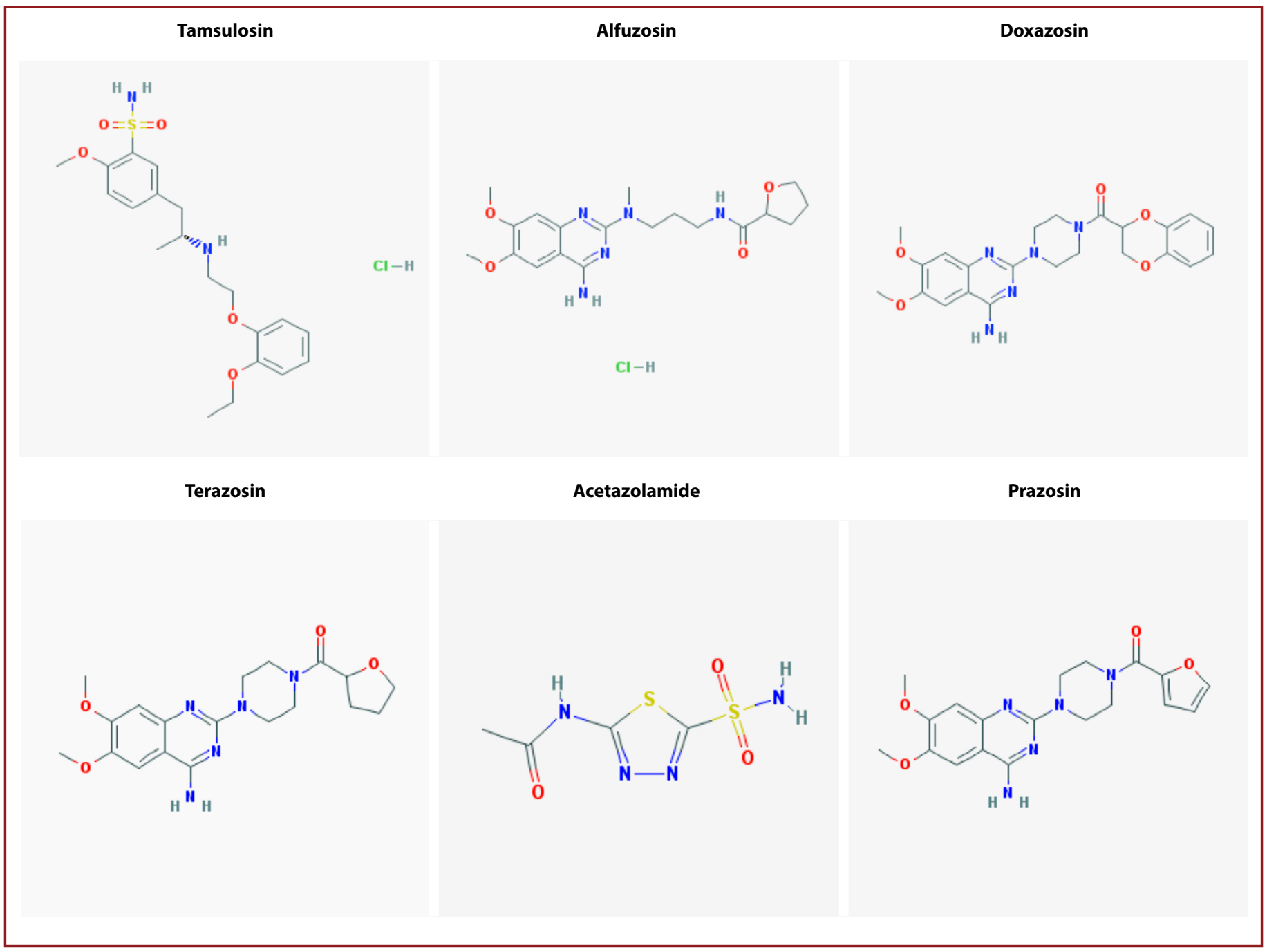

Figure 1. Chemical formulas of tamsulosin, alfuzosin, doxazosin, terazosin, prazosin, and acetazolamide. 
Table 1. Comparative analysis of the mechanisms and effects of tamsulosin, other adrenergic receptor and acetazolamide antagonists

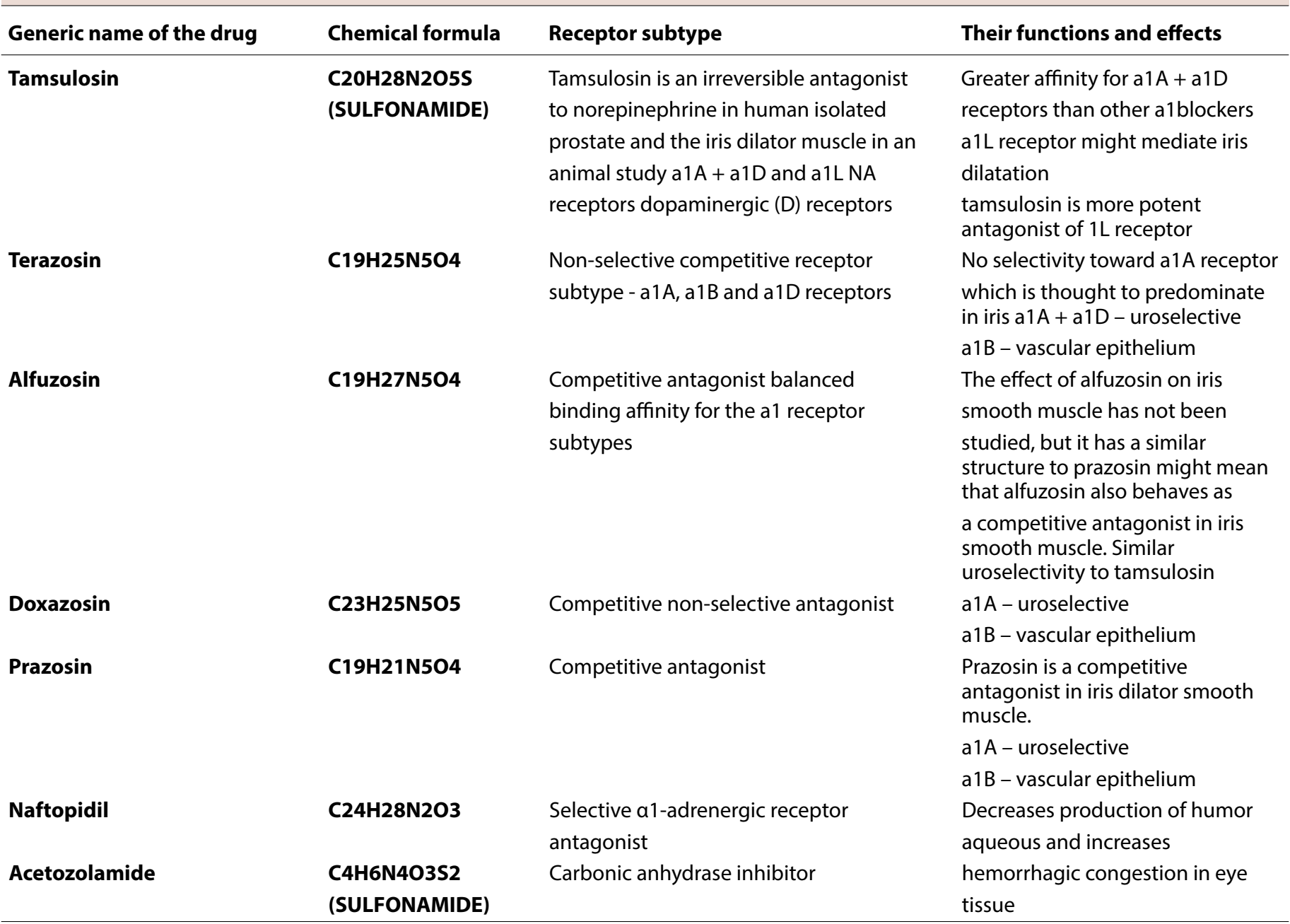

\section{Discussion}

IFIS, a recently defined syndrome characterized by small pupil, should be considered in cases of inadequate pupillary dilatation before surgery as well as cases of intraoperative progressive myosis. Even though IFIS has been reported in $0.6 \%-2.0 \%$ of the population in general, its incidence has been reported to be $57 \%-100 \%$ among the male population undergoing tamsulosin therapy ${ }^{[3]}$.

Although the precise mechanism through which tamsulosin can lead to IFIS remains unknown, Chang et al. ${ }^{[1]}$ have suggested that tamsulosin has a high affinity and specificity for a-1A AR, which is thought to be the dominant receptor in the IRIS. They have discussed data pertaining to a retrospective and another prospective study, which support an association between tamsulosin and IFIS. In the retrospective arm of the study on IFIS, 16 of the 511 patients were using tamsulosin, and 10 of these 16 patients (63\%) had IFIS, whereas none of the 11 patients using a-1 antag- onists other than tamsulosin had IFIS. In the prospective arm of the same study performed on 741 patients, IFIS was observed in 16 patients (2.2\%), and 15 of these 16 patients (94\%) were either currently using tamsulosin or had used tamsulosin for some time ${ }^{[1]}$. Chang et al. ${ }^{[15]}$ noted that IFIS was not observed in patients using tamsulosin for less than 4-6 months, and in the surgical population with IFIS, sphincterotomy and mechanical pupillary dilatation maneuvers performed to provide proper pupillary dilatation were ineffective. In another study including 332 patients, 64 patients were either still using tamsulosin or alfuzosin or had previously used and discontinued it. IFIS was seen in 19 out of 22 patients (86.4\%) using tamsulosin on an average of 38 months, and at the same time, IFIS was observed in only 2 out of 13 patients (15.4\%) using alfuzosin for 20 months on an average. In 5 patients using tamsulosin, although the drug was stopped 2 months before surgery, as recommended by an ophthalmologist, IFIS was observed in all patients ${ }^{[3]}$. Nonetheless, in the literature, IFIS was ob- 
served in a patient who did not use any other a-1 antagonist after the discontinuation of his tamsulosin therapy 3 years before surgery ${ }^{[16]}$. Therefore, tamsulosin is thought to exert irreversible effects on iris muscles. Although IFIS was encountered in patients who discontinued tamsulosin 1 year before surgery, many eye centers of UK discontinue tamsulosin use at least 2 weeks before cataract surgery and suggest the reinstitution of tamsulosin therapy immediately after surgery ${ }^{[17]}$. In another study, despite the discontinuation of tamsulosin use 7-28 days before surgery, floppy iris tissue was detected in these patients ${ }^{[18]}$. Therefore, a consensus has not been reached on the timing of the cessation of tamsulosin use. Animal studies have demonstrated 24-times stronger a-1 affinity of tamsulosin to $\mathrm{a}-1 \mathrm{~A}$ relative to $\mathrm{a}-1 \mathrm{~B}{ }^{[19]}$. Besides, it has been observed that tamsulosin remains relatively longer in the anterior chamber, and during its half-life of 48-72 hours, it induces relatively permanent blockade with resultant atrophy of iris dilator smooth muscle ${ }^{[1]}$. This phenomenon explains floppy iris syndrome observed after the cessation of the drug. However, tamsulosin users should cease using this drug as early as possible before cataract surgery. Precise information about the duration of its use is lacking. Taben et al. ${ }^{[20]}$ have reported a case of IFIS after 1 day of tamsulosin (1 dose) therapy, indicating that a-1 blockade alone without disuse atrophy could be enough to cause IFIS. Shah et al. ${ }^{[21]}$ have also published a case of IFIS occurring only 2 days after tamsulosin was initiated.

The most comprehensive review of ARs in relation to the potential pathophysiology of IFIS was recently published ${ }^{[22]}$. The a-1 receptor subgroups of dilator smooth muscles of the human iris had not been determined yet ${ }^{[1]}$. However, detailed findings have demonstrated their resemblance to those of rabbits. In some studies performed in rabbits, a dominance of $a-1$ ARs and especially $a-1 A$ subtype in dilator muscles of iris has been detected ${ }^{[23,24]}$. However, in another study performed on rabbits, the presence of $\mathrm{a}-1 \mathrm{~A}$ $(60 \%)$ and $\mathrm{a}-1 \mathrm{~B}(40 \%)$ subtypes was demonstrated ${ }^{[25]}$. There are 3 subtypes of $a-1$ ARs a1A, a1B, and a1D all of which have been cloned and characterized ${ }^{[26]}$. A fourth subtype a1L AR has been pharmacologically defined but not fully characterized or cloned yet. Tiwari et al. ${ }^{[27]}$ have also proposed an important role of the a $1 \mathrm{~L}$ subtype receptor in the mediation of iris dilatation in the human eye, and tamsulosin was considered to be a more potent antagonist of this receptor subtype rather than terazosin or doxazosin. As the exact mechanism by which tamsulosin induces IFIS is yet to be established, the role of other non-ARs (i.e., dopaminergic and serotonergic receptors) in inducing pupillary changes warrants consideration [28-31]. Tamsulosin seems to have a potent affinity with dopaminergic receptors as well ${ }^{[32]}$. Tamsulosin is a chiral molecule. An animal study has shown one form to be 140 times more potent in the prostate than the other ${ }^{[33]}$. The more potent form is an irreversible antagonist of norepinephrine in human isolated prostate ${ }^{[34]}$ and the iris dilator muscle as shown in an experimental animal study ${ }^{[35]}$. However, in another study, it has been advocated that the blocking effect of tamsulosin on the a-1 receptors on iris tissue can be prevented by binding these receptors with the natural agonist epinephrine. For this purpose, epinephrine was administered to the anterior chamber, and it was observed that iris dilator muscle tonus and iris rigidity increased thereafter ${ }^{[36]}$. Structural differences and well-defined mechanisms of action of AR antagonists might account for substantial differences in cases of IFIS. Alfuzosin has been reported to show selectivity only for the a1A subtype ${ }^{[37]}$, and act as a pure competitive antagonist in human prostatic smooth muscle [38], as do terazosin ${ }^{[34]}$ and prazosin ${ }^{[39]}$. Similar to prazosin ${ }^{[40]}$, alfuzosin behaves as a competitive antagonist in human iris smooth muscle. Settas et al. ${ }^{[41]}$ have suggested that the overall affinity of a1 AR antagonists toward a1A receptors might explain IFIS. Figure 1 compares the mechanisms and effects of tamsulosin and other AR antagonists. In addition, Schwinn et al. ${ }^{[12]}$ have proposed that IFIS might be associated with various diseases and medications. They have stated that in animal studies, nitric oxide has been shown to relax iris sphincter and dilator smooth muscle. Daily use of a nitroglycerin patch could be another potential cause of IFIS. However, there are no clinical cases or human studies showing an association of nitrates and IFIS. The a-1 AR-mediated iris dilator smooth muscle contraction occurs due to a1A ARs, whereas iris arteriolar contraction occurs due a1B ARs. After reviewing IFIS, strengths/weaknesses of supporting data, and iris biology, a case is made that rather than being drug-specific (a1AR antagonists), IFIS may represent the "tip of the iceberg." Relaxed iris dilator muscle resistant to adrenergic agonists should be expected to develop by the use of drugs with mydriatic activity (e.g., antagonists at a1 $A R$, endothelin- $A$, angiotensin receptors, and nitric oxide donors such as nitrates) and/or diseases associated with endothelial dysregulation (e.g., congestive heart failure, diabetes, and hypertension). Rather than a rare, unexpected, unpredictable syndrome due to one drug, a careful medical history should elucidate predisposing factors of IFIS. Just as anticoagulants are discontinued prior to elective surgery, in consultation with the patient's primary physician, discontinuation of drugs with mydriatic activity used in the 
conservative management of elderly patients should be considered prior to cataract surgery ${ }^{[12]}$. Some researchers have suggested that iris contraction and relaxation is the result of a balance of competing for neural pathways and pathways regulated by prostaglandin and nitric oxide ${ }^{[42,}$ 43]. Carbonic anhydrases (CAs) constitute a group of enzymes with a physiological importance, which are widely distributed in the body. It has been demonstrated that CA has 14 iso-enzymes. In humans, type I, II, and IV were detected in the eye. Types 1 and II are localized in cell cytoplasm, while type IV is bound to cell membranes. None of the currently used clinical drugs exhibit selectivity for a specific CA isoform. In a study to design selective sulfonamides, two complementary approaches have been proposed: "ring" and "tail" [44]. It is clear that balanced hydro- and liposolubility is required for optimum in vivo activity since therapeutically useful anti-glaucoma medications are aromatic and heterocyclic sulfonamides. One of the conditions necessary for a sulfonamide to act as an effective intraocular pressure reducing agent is the presence of moderate lipid solubility ${ }^{[45]}$. Acetazolamide is a potent carbonic anhydrase inhibitor. Acetazolamide is not a mercury-based diuretic. It is a non-bacteriostatic sulfonamide with a chemical structure and pharmacological effectiveness quite different from bacteriostatic sulfonamides. CAls are believed to cause vasodilation by increasing intracytoplasmic $\mathrm{CO}_{2}$ levels. A $37 \%$ increase in retinal blood flow has been demonstrated by the systemic use of acetazolamide ${ }^{[46]}$.

\section{Conclusion}

Sulfonamide group is a component present in the structure of acetazolamide, which exerts vasodilatory effects on relaxation of the vascular smooth muscle of the eye, and tamsulosin, which relaxes the urethral smooth muscle in $\mathrm{BPH}$ treatment. In addition, although this study cannot make a definitive decision, our findings suggest that sulfonamide group in tamsulosin may explain the specific pathophysiology of IFIS. However, we believe that there is a need for more extensive studies on this topic. Clarification of this issue from a pharmacokinetic perspective can conceivably decrease this peculiar and prevalent side effect of this drug, which imposes challenging difficulties to ophthalmologists.

Peer-review: Externally peer-reviewed.

Authorship Contributions: Concept: A.U., O.H.Y.; Design: A.U., O.H.Y.; Data Collection or Processing: A.U., O.H.Y.; Analysis or Interpretation: A.U., O.H.Y.; Literature Search: A.U., O.H.Y.; Writing: A.U., O.H.Y.

Conflict of Interest: None declared.
Financial Disclosure: The authors declared that this study received no financial support.

\section{References}

1. Chang DF, Campbell JR. Intraoperative floppy iris syndrome associated with tamsulosin. J Cataract Refract Surg 2005;31:664-73. [CrossRef]

2. Nguyen DQ, Sebastian RT, Kyle G. Surgeon's experiences of the intraoperative floppy iris syndrome in the United Kingdom. Eye (Lond) 2007;21:443-4. [CrossRef]

3. Blouin MC, Blouin J, Perreault S, Lapointe A, Dragomir A. Intraoperative floppy-iris syndrome associated with alpha1-adrenoreceptors: comparison of tamsulosin and alfuzosin. J Cataract Refract Surg 2007;33:1227-34. [CrossRef]

4. Dhingra N, Rajkumar KN, Kumar V. Intraoperative floppy iris syndrome with doxazosin. Eye (Lond) 2007; 21:678-9. [CrossRef]

5. Venkatesh R, Veena K, Gupta S, Ravindran RD. Intraoperative floppy iris syndrome associated with terazosin. Indian J Ophthalmol 2007;55:395-6. [CrossRef]

6. Issa SA, Dagres E. Intraoperative floppy-iris syndrome and finasteride intake. J Cataract Refract Surg 2007;33:2142-3. [CrossRef]

7. Calotti F, Steen D. Labetalol causing intraoperative floppy-iris syndrome. J Cataract Refract Surg 2007;33:170-1. [CrossRef]

8. Ugarte $\mathrm{M}$, Leong $\mathrm{T}$, Rassam $\mathrm{S}$, Kon $\mathrm{CH}$. Intraoperative floppyiris syndrome, alpha1-adrenergic antagonists, and chronic intake of mianserin: Is there an association? J Cataract Refract Surg 2007;33:170. [CrossRef]

9. Unal M, Yücel I, Tenlik A. Intraoperative floppy-iris syndrome associated with chronic use of chlorpromazine. Eye (Lond) 2007;21:1241-2. [CrossRef]

10. Papadopoulos R, Bachariou A. Intraoperative floppy-iris syndrome associated with chronic intake of donepezil. J Cataract Refract Surg 2007;33:1997-8. [CrossRef]

11. Pringle E, Packard R. Antipsychotic agent as an etiologic agent of IFIS. J Cataract Refract Surg 2005;31:2240-1. [CrossRef]

12. Schwinn DA, Afshari NA. alpha(1)-Adrenergic receptor antagonists and the iris: new mechanistic insights into floppy iris syndrome. Surv Ophthalmol 2006;51:501-12. [CrossRef]

13. Yeu E, Grostern R. Saw palmetto and intraoperative floppy-iris syndrome. J Ctaract Refract Surg 2007;33:927-8. [CrossRef]

14. Ishiguro M, Futabayashi Y, Ohnuki T, Ahmed M, Muramatsu I, Nagatomo T. Identification of binding sites of prazosin, tamsulosin and KMD-3213 with alpha(1)-adrenergic receptor subtypes by molecular modeling. Life Sci 2002;71:2531-41. [CrossRef]

15. Chang DF. The Intraoperative floppy iris syndrome, Cover Story. Cataract and Refractive Surg Today 2005;4:64-8.

16. Osher RH. Association between IFIS and Flomax. J Cataract Refract Surg 2006;32:547. [CrossRef]

17. Brogden PR, Backhouse OC, Saldana M. Intraoperative floppy iris syndrome associated with tamsulosin. Can Fam Physician 2007;53:1148

18. Pärssinen $O$, Leppänen $E$, Keski-Rahkonen $P$, Mauriala $T$, Dugué $B$, Lehtonen $M$. Influence of tamsulosin on the iris and its implications for cataract surgery. Invest Ophthalmol Vis Sci 
2006;47:3766-71. [CrossRef]

19. Chadha V, Borooah S, Tey A, Styles C, Singh J. Floppy iris behaviour during cataract surgery: associations and variations. Br J Ophthalmol 2007;91:40-2. [CrossRef]

20. Taben R, Thakuria P, Jones M, Lohman LE: Intraoperative floppy-iris syndrome after one day of tamsulosin therapy. Available at: http://stream.expoplanner.com/ascrs2007/powerpoints/000092_IFIS_Case_ASCRS_Presentation.ppt.

21. Shah N, Tendulkar M, Brown R. Should we anticipate intraoperative floppy iris syndrome (IFIS) even with very short history of tamsulosin? Eye (Lond) 2009;23:740. [CrossRef]

22. Srinivasan S, Radomski S, Chung J, Plazker T, Singer S, Slomovic AR. Intraoperative floppy-iris syndrome during cataract surgery in men using alpha-blockers for benign prostatic hypertrophy. J Cataract Refract Surg 2007;33:1826-7. [CrossRef]

23. Nakamura S, Taniguchi T, Suzuki F, Akagi Y, Muramatsu I. Evaluation of alpha1-adrenoceptors in the rabbit iris: pharmacological characterization and expression of mRNA. Br J Pharmacol 1999;12:1367-74. [CrossRef]

24. Suzuki F, Taniguchi T, Nakamura S, Akagi Y, Kubota C, Satoh M, et al. Distribution of alpha-1 adrenoceptor subtypes in RNA and protein in rabbit eyes. Br J Pharmacol 2002;135:600-8. [CrossRef]

25. Wikberg-Matsson A, Uhlén S, Wikberg JE. Characterization of alpha(1)-adrenoceptor subtypes in the eye. Exp Eye Res 2000;70:51-60. [CrossRef]

26. Hieble JP, Bylund DB, Clarke DE, Eikenburg DC, Langer SZ, Lefkowitz RJ, et al. International Union of Pharmacology. X. Recommendation for nomenclature of alpha 1-adrenoceptors: consensus update. Pharmacol Rev 1995;47:267-70.

27. Tiwari A. Tamsulosin and floppy iris syndrome in benign prostatic hyperplasia patients. Expert Opin Investig Drugs. 2006; 15:443-446. [CrossRef]

28. Fanciullacci $M$, Sicuteri R, Alessandri M, Geppetti P. Buspirone, but not sumatriptan, induces miosis in humans: relevance for a serotoninergic pupil control. Clin Pharmacol Ther 1995;57:349-55. [CrossRef]

29. Pringle E, Packard R. Antipsychotic agent as an etiologic agent of IFIS. J Cataract Refract Surg 2005;31:2240-1. [CrossRef]

30. Giuliano F. Impact of medical treatments for benign prostatic hyperplasia on sexual function. BJU Int 2006;97 Suppl 2:34-8.

31. Clément $P$, Bernabé J, Kia HK, Alexandre L, Giuliano F. D2-like receptors mediate the expulsion phase of ejaculation elicited by 8-hydroxy-2-(di-N-propylamino)tetralin in rats. J Pharmacol Exp Ther 2006;316:830-4. [CrossRef]

32. Leonardi A, Hieble JP, Guarneri L, Naselsky DP, Poggesi E, Sironi $\mathrm{G}$, et al. Pharmacological characterization of the uroselective alpha-1 antagonist Rec 15/2739 (SB 216469): role of the alpha-1L adrenoceptor in tissue selectivity, part I. J Pharmacol Exp Ther 1997;281:1272-83.
33. Honda K, Nakagawa C. Alpha-1 adrenoceptor antagonist effects of the optical isomers of YM-12617 in rabbit lower urinary tract and prostate. Journal of Pharmacology and Experimental Therapeutics 1986;239:512-6.

34. Muramatsu I, Taniguchi T, Okada K. Tamsulosin: alpha1-adrenoceptor subtype-selectivity and comparison with terazosin. Jpn J Pharmacol 1998;78:331-5. [CrossRef]

35. Takayanagi I, Konno F, Kameda H, Kubo H, Furukawa A, Toyoda T. A difference in mode of antagonism between optical isomers of a potent selective alpha 1-adrenoceptor blocker (YM-12617) and norepinephrine in isolated rabbit iris dilator and aorta. Jpn J Pharmacol 1986;42:579-82. [CrossRef]

36. Shugar JK. Use of epinephrine for IFIS prophylaxis. J Cataract Refract Surg 2006;32:1074-5. [CrossRef]

37. Martin DJ, Angel I, Arbilla S. Functional uroselectivity. Eur Urol 1998;33:12-8. [CrossRef]

38. Palea S, Barras M, Deplanne V, Vallancien G. Antagonistic effects of alfuzosin on concentration-response curves to phenylephrine and noradrenaline in human prostatic adenoma. Neurourol Urodyn 2000;19:431-3.

39. Teng CM, Guh JH, Ko FN. Functional identification of alpha 1-adrenoceptor subtypes in human prostate: comparison with those in rat vas deferens and spleen. Eur J Pharmacol 1994;265:61-6. [CrossRef]

40. Ishikawa $H$, Miller DD, Patil PN. Comparison of post-junctional alpha-adrenoceptors in iris dilator muscle of humans, and albino and pigmented rabbits. Naunyn Schmiedebergs Arch Pharmacol 1996;354:765-72. [CrossRef]

41. Settas G, Fitt AW. Intraoperative floppy iris syndrome in a patient taking alfuzosin for benign prostatic hypertrophy. Eye (Lond) 2006;20:1431-2. [CrossRef]

42. Chuman T, Chuman H, Nao-i N, Sawada A, Yamamoto R, Wada A. Nitric oxide-sensitive and -insensitive contractions of the isolated rabbit iris sphincter muscle. Invest Ophthalmol Vis Sci 1996;3:1437-43.

43. Pianka P, Oron Y, Lazar M, Geyer O. Nonadrenergic, noncholinergic relaxation of bovine iris sphincter: role of endogenous nitric oxide.Invest Ophthalmol Vis Sci 2000;41:880-6.

44. Yorulmaz N, Oltulu O, Eroğlu E. Development of selective QSAR models and molecular docking study for inhibitory activity of sulfonamide derivatives against carbonic anhydrase isoforms II and IX. Journal of Molecular Structure 2018;1163:270-9. [CrossRef]

45. Remko M. Molecular structure, pKa, lipophilicity, solubility and absorption of biologically active aromatic and heterocyclic sulfonamides. Journal of Molecular Structure THEOCHEM 2010;944:34-42. [CrossRef]

46. Rassam SM, Patel V, Kohner EM. The effect of acetazolamide on the retinal circulation. Eye (Lond) 1993;7:697-702. [CrossRef] 